\title{
ДОВЕРИЕ В ОРГАНИЗАЦИОННОЙ КУЛЬТУРЕ: КУЛЬТУРНО-ЦЕННОСТНЫЙ ГОРИЗОНТ (ДИСКУРС) АНАЛИЗА
}

\author{
Моисеенко Мария Сергеевна, \\ mishutina@tpu.ru \\ Национальный исследовательский Томский политехнический университет, \\ Россия, 634050, г. Томск, пр. Ленина, 30
}

\begin{abstract}
Моисеенко Мария Сергеевна, начальник управления корпоративных и внешних коммуникаций Национального исследовательского Томского политехнического университета.

Дан анализ доверия как социального капитала, социального кредита, необходимого компонента солидарности. Раскрыты понятия меры и гранищы доверия. Обозначен статус доверия как искусства коммуникативной политики. Показано, что порог доверия, его мера и потенциал определяются императивами доверия, в числе которых результативность, порядочность, забота.
\end{abstract}

Ключевые слова: Доверие, социальный капитал, социальный кредит, ценность, компонент солидарности, потенциал доверия, искусство коммуникативной политики, императивы доверия, результативность, порядочность, забота.

Актуальность исследования феномена лидерства обусловлена значимостью статуса лидеров в жизни современного общества. Потенциал этого ресурса в сфере управления подтверждён по сути всем цивилизационным развитием. Интерес к обозначенному феномену появляется во времена античности. Много веков спустя, благодаря промышленной революции, охватившей США и страны европейского континента, был сформирован интерес к проблеме лидерства (от англ. leader - ведущий, руководитель), который впоследствии превратился в проблему, требующую решения. Формирование и поиск способов быстро реагировать на ситуацию, находить рационально обусловленные решения, трансформировать управленческую деятельность в максимально эффективную, именно лидеры обнаружили данные компетенции и способности. В условиях, сделавших очевидной значимость лидерства в решении проблем управления, актуальными стали и изучение теории и практики лидерства, исследование процессов социокультурного осмысления этого феномена, анализ ценностных теорий, в дискурсе которых лидерство превратилось в предмет анализа.

Если попытаться определить единый вектор исследовательского интереса к феномену лидерства, его можно обозначить формулой «от поведенческой модели к культурноценностной парадигме», сформулированной А.Н. Занковским [1]. Именно эта формула раскрывает парадигмальную направленность сдвигов в формирующихся сегодня концептуальных версиях изучения феномена лидерства. Эти парадигмальные трансформации в основе своей обусловлены изменением объекта исследования - лидера.

Сегодня лидер, по определению А. Менегетти [2], превращен в интегрального человека для интегрального мира.

«Глобализация, - пишет автор, - день за днём учит нас тому, что мир может быть личностью; прежде чем заниматься разумом некоего народа, нужно воспитать личность. Мы являемся свидетелями столь продвинутой стадии прогресса, которая оказалась не по 
силам нашим институтам... они не могут координировать её. Я хотел бы, чтобы лидеры научились живо чувствовать это. Лидер - это человек, умеющий реализовывать личный и социальный рост в целях глобального прогресса сообщества, а следовательно, это ум способного человека, который умеет интегральным образом... служить функциональности других.

Лидер - это интегральный человек для интегрального мира... Лидер, поднявшись над своей зрелостью, увидит также и перспективу прогресса как такового» [2, с. 74].

Сегодня проблема лидерства вышла за рамки психологии и той поведенческой модели, контур и горизонт которой в середине XX в. обозначили исследования К. Левина, Р. Босейка, Дж. Мутона, Ф. Фиджера, Р. Лайкерта, Дж. Мисуми. Аналитики пишут о происшедшей трансформации этого феномена, затронувшей сущность и функции лидерства. Лидерство, отмечает, к примеру А. Н. Занковский, всё больше выступает идеальной моделью человеческого поведения, являясь для миллионов ориентиром. И в то время как обозначенные теории лидерства, созданные названными выше авторами, могут и должны рассматриваться как результат анализа малых групп, а само лидерство в этой ситуации интерпретировано в статусе группового явления в контексте групповой динамики, сегодня как полагает, к примеру, А.Н. Занковский, пределы группы оказываются для исследователя достаточно узки. Мы считаем, что расширение масштабов анализа лидерства, раздвинутость исследовательского горизонта обусловлены новым подходом к этому феномену, в основании которого положена интерпретация лидерства как организационного процесса. И в рамках такого подхода необходимо рассмотреть «контекст целостной организации и её системных характеристик» [1, с. 270], в том числе, как мы полагаем, и ценностных характеристик.

Между тем традиционные подходы, которые ориентированы на рассмотрение лидерства «... как технологии поведения в контексте ограниченного набора ситуационных переменных», привели «.... к потере личности лидера, его субъектности» [1, с. 270].

Обозначенная ситуация привела к оформлению новой парадигмы исследования, в основание которой положено понятие так называемого «организационного лидерства».

Предлагая и развивая этот подход как максимально эффективный, его создатели, одним из которых является А.Н. Занковский, осуществляющий исследовательские нюансы (включая миниатюрные и кросс-культурные исследования в течение трёх десятилетий), исходят из того, что структуру и функции организационного лидерства возможно понять и объяснить лишь в рамках системы власти в организации; лидерство - та организационная власть, которая реализуется за счёт личностных ресурсов. Условием и предпосылкой эффективного лидерства являются ценностные ориентации. Они названы А.Н. Занковским «личностными переменными» [1, с. 271].

Посредством обозначенного подхода (в том числе, посредством обращения к потенциалу психосемантического метода исследования - Е.Ю. Артемьева, В.Ф. Петренко, А.Г. Шмелев, А.Н. Занковский), делая акцент на индивидуальных системах ценностных значений и смыслов, анализирующие феномен лидерства видят систему ценностных маркеров, находящих применение в действиях лидера. Важно, что с помощью обозначенного подхода выявляются те глубинные ценностные координаты, что проявляют себя в деятельности лидера; новый подход позволяет также сформировать трёхфазную модель лидерства, в которой чётко просматриваются важные для деятельности лидера составляющие ориентация на задачу, людей и вектор культурно-ценностного измерения.

Рассмотрим с позиций культурно-ценностного подхода роль и значение феномена доверия в системе организационного лидерства, обозначив его статус в системе отношений лидерства. По Л. Гудкову, доверие - «это закрытое социальное взаимодействие» [3, 
с. 19]. Его структура основана на соединении различных по своей сути смысловых оснований. Однако независимо от этого различия смысловых оснований во всех тех случаях, где проявляет себя феномен доверия, имеет место пред-понимание ситуации, её определение и схематизация действия. Это пред-понимание заключено в актуализации горизонтов действия и возможных способов поведения своего и партнера.

Л. Гудков определяет доверие как «... способность актора схватывать выражение имплицитных кодов и правил поведения одних институтов или социальных групп в зонах действия других институциональных или групповых правил, это восприятие действующим «шифром» не называемых, но предполагаемых, подразумеваемых в конкретной ситуации взаимодействия норм институционального действия, которыми будет руководствоваться партнёр, поскольку предполагается, что он должен, обязан это делать» [3, c. 19].

Именно так понимаемое доверие определяет смысл будущего; доверие в широком смысле - это социальное взаимодействие. Как правило, вектором его проявления является ориентация на вероятность, на веру в то, что действия партнёров будут соответствовать тому порядку, который ожидается субъектом действия (в нашем случае этим субъектом действия является лидер). Сам же порядок основан на взаимных моральных либо ценностных обязательствах, на принуждении. В основании обозначенного порядка положены конвенции, убеждения, интересы. При этом вера в то, что действия партнёров будут соответствовать ожидаемому субъектом действия порядку, может подтверждаться санкциями, назначаемыми в ситуации, если ожидания окажутся нарушенными, а принятые обязательства (они имеют, как правило, нормативно-правовой характер) окажутся невыполненными.

Огромную роль в системе обозначенных обязательств играет согласие; ценностные обязательства, как правило, основаны на согласии. Это может быть согласие по вопросам самого разного рода: например, по вопросам, связанным с этическими нормами, с ответственностью за нарушение правил коллективной жизни сообщества.

Горизонт философского понимания доверия включает в себя множество интерпретаций. Создавшие эти версии полагают, что мир человеческих отношений строится на присутствии в нём того, что создано процессом социального взаимодействия. Это своего рода форма духовной близости, составляющая солидарности - пишет, обращаясь к идее доверия, о «социальном капитале», К. Эрроу. Представление о доверии, созданное в горизонте философского знания, ориентировано на этическую составляющую: на долг, совесть, солидарность. Однако ситуация изменилась тогда, когда в проблемном поле коммуникативной онтологии социальности возникло новое представление о специфике управленческого сегмента. В обществе, приобретающем характер коммуникативно-организованной целостности, мера и сила доверия имеют большую значимость, поскольку у него появился статус «искусства ассоциативно-коммуникативной политики» (термин впервые предложен Г.Н. Петровой в [4]). В таком статусе оно превращается в одну из форм социальной солидарности.

В определении масштабов эффективности доверия в системе отношений «лидерсообщество» важен учёт факторов, составляющих группу его императивов, в числе которых особую роль играют результативность, порядочность, забота. Их смысл заключён в следующем:

- доверие всегда связано с представлением о действиях; эти действия совершаются тем, кому доверяют, и эти действия должны быть результативными; люди не способны сохранять доверие, если результаты действий лидера не оправдывают ожиданий;

- порядочность - её влияние на доверие является важным тогда, когда каждая из сторон определяет для себя возможность и масштаб риска в отношениях с партнёром; 
- забота порождает веру в тех, кто способен поддержать наше благополучие. Принцип заботы связан с моментом ожидания: тот, на кого направлено наше доверие, лоялен к нашим интересам и в случае, если будущие события породят желание поступать иначе.

Влияют ли императивы доверия в единой системе друг на друга и каков масштаб этого влияния? Утвердительно ответив на этот вопрос и даже отменив возможность конфликта императивов, приведём в подтверждение возможности влияния рассуждение Р.Б. Шо, полагающего, что «... императивы доверия влияют друг на друга; очень низкие показатели по результативности, порядочности или проявлению заботы могут затормозить прогресс в других сферах деятельности и подорвать доверие. Руководителям, которые добиваются хороших результатов, но делают это недостаточно порядочными методами, не будут доверять. Но бывает и обратная ситуация, когда доверие сохраняется и при слабой (но не гибельной для компании) реализации одного из императивов, если это компенсируется высокой эффективностью двух других. Например, лидеры иногда могут компенсировать непоследовательность действий, если действуют результативно и проявляют заботу о своих сотрудниках. Другими словами, для людей иногда недостаток в одной области доверия может компенсироваться особо эффективной деятельностью в двух других областях. Однако такие случаи всё же являются исключениями» [5, с. 57].

Принимая решения, связанные с риском, лидер оказывается в ситуации, которая характеризуется балансом потребностей. Этот баланс возникает за счёт создания (путём обращения к доверию) отношений, основанных на поддержке. И, кроме того, баланс потребностей возникает посредством уменьшения своей уязвимости через недоверие.

Доверие, таким образом, играет роль мощного фактора управления, который трудно переоценить, когда речь идёт о решении проблем, связанных с эффективной работой адаптационных механизмов, с высокой степенью реализации возможностей человеческого капитала, - совокупности знаний, умений, навыков, инновационности. Доверие позволяет сформировать атмосферу согласия, систему мотивационных механизмов; снижает масштаб рискованности, играя роль существенного катализатора организационных трансформаций, и превращает организацию в по-настоящему гармоничную целостность.

\section{СПИСОК ЛИТЕРАТУРЫ}

1. Занковский А.Н. Психология лидерства. От поведенческой модели к культурно-ценностной парадигме. - М.: Институт психологии РАН, 2011. - 296 с.

2. Менегетти А. Психология лидера. - М.: Оптопсихология, 2004. - 256 с.

3. Гудков Л. Доверие в России: смысл, функции, структура // Вестник общественного мнения. - 2012. № 2 (112). - С. 8-42.

4. Петрова Г.И. Открытое образовательное пространство в контексте коммуникативной рациональности: методологические подходы к практике управленческой деятельности в образовании. URL: http://vital.lib.tsu.ru/vital/access/manager/Repository/vtls:000477902 (дата обращения 12.02.2021).

5. Шо Р.Б. Ключи к доверию в организации: результативность, порядочность, проявление заботы. - М.: Дело, 2000. - 272 с.

Поступила 20.02.2021 г. 
UDC 304.442

\title{
TRUST IN ORGANIZATIONAL CULTURE: CULTURAL VALUE HORIZON (DISCOURSE) OF ANALYSIS
}

\author{
Maria S. Moiseenko, \\ mishutina@tpu.ru
}

National Research Tomsk Polytechnic University, 30, Lenin avenue, Tomsk, 634050, Russia

Maria S. Moiseenko, Head of Corporate and External Communications Department, National Research Tomsk Polytechnic University.

The article analyzes trust as social capital, social credit, necessary component of solidarity. The concepts of measure and boundaries of trust are revealed. The status of trust as «the art of communicative politics» is designated. It is shown that the "threshold» of trust, its measure and potential are determined by the imperatives of trust, including efficiency, decency, and concern.

Key words: Trust, social capital, social credit, value, component of solidarity, potential of trust, art of communication policy, imperatives of trust, efficiency, decency, care.

\section{REFERENCES}

1. Zankovskiy A.N. Psikhologiya liderstva. Ot povedencheskoy modeli $k$ kulturno-tsennostnoy paradigme [Leadership psychology. From a behavioral model to a cultural value paradigm]. Moscow, Institut psikhologii RAN Publ., 2011. 296 c.

2. Menegetti A. Psikhologiya lidera [Psychology of a leader]. Moscow, Optopsikhologiya Publ., 2004. 256 p.

3. Gudkov L. Doverie v Rossii: smysl, funktsii, struktura [Trust in Russia: meaning, functions, structure]. Vestnik obshchestvennogo mneniya, 2012, no. 2 (112), pp. 8-42.

4. Petrova G.I. Otkrytoe obrazovatelnoe prostranstvo $v$ kontekste kommunikativnoy ratsionalnosti: metodologicheskie podkhody $k$ praktike upravlencheskoy deyatelnosti v obrazovanii [Open educational space in the context of communicative rationality methodological approaches to the practice of management activities in education]. Available at: http://vital.lib.tsu.ru/vital/access/manager/Repository/vtls:000477902 (accessed 12 February 2021).

5. Sho R.B. Klyuchi $k$ doveriyu v organizatsii: rezultativnost, poryadochnost, proyavleniye zaboty [Keys to trust in an organization: effectiveness, decency, concern]. Moscow, Delo Publ., 2000. 272 p.

Received: 20 February 2021. 